\title{
USING PHASE FIELD AND THIRD-ORDER SHEAR DEFORMATION THEORY TO STUDY THE EFFECT OF CRACKS ON FREE VIBRATION OF RECTANGULAR PLATES WITH VARYING THICKNESS
}

\author{
Pham Minh Phuc* \\ University of Transport and Communications, No 3 Cau Giay Street, Hanoi, Vietnam
}

\author{
ARTICLE INFO \\ TYPE: Research Article \\ Received: $21 / 7 / 2020$ \\ Revised: $14 / 9 / 2020$ \\ Accepted: 28/9/2020 \\ Published online: 30/9/2020 \\ https://doi.org/10.47869/tcsj.71.7.10 \\ * Corresponding author \\ Email: phamminhphuc@utc.edu.vn
}

\begin{abstract}
The paper presents the studies on the free vibration of a rectangular plate with one or more cracks. The plate thickness varies along the X-axis with linear rules. Using Shi's thirdorder shear deformation theory and phase field theory to set up the equilibrium equations, which are solved by finite element methods. The frequency of free vibration plates is calculated and compared with the published articles, the agreement between the results is good. Then, the paper will examine the free vibration frequency of plate depending on the change of the plate thickness ratio, the length of cracks, the number of cracks, the location of cracks and different boundary conditions.
\end{abstract}

Keywords: rectangle plate, varying thickness, crack, vibration, finite element method, HSDT, phase field theory.

(C) 2020 University of Transport and Communications

\section{INTRODUCTION}

Variable thickness could affect the design of the plate structure as it allows to adjust the stiffness in the most stressed areas in the plate while keeping the weight constant. The problem with the vibration of plate with variable thickness is studied by many authors. T. Sakiyama and M. Huang [1] employed the approximate method which was based on the Green function to investigate the free vibration of thin and moderate thick rectangular plates with arbitrary variable thickness. Using the polynomial and harmonic differential quadrature 
methods, Malekzadeh et al. [2] analyzed free vibration of variable thickness thick skew plates. I. Shufrin and M. Eisenberger [3] determined the free vibration of shear deformable plates with variable thickness using the first-order shear deformation plate theory of Mindlin (FSDT) and the higher-order shear deformation plate theory of Reddy. The FSDT and the exact element method were employed by Efraim et al. [4] to analyze the exact vibration of variable thickness thick annular isotropic and FGM plates. Gupta et al. [5] studied the free vibration of non-homogeneous circular plates of variable thickness using FSDT. Vahid et al. [6] investigated three-dimensional free vibration of thick circular and annular isotropic and functionally graded plates with variable thickness along the radial direction based on the linear, small strain and exact elasticity theory. Michele Bacciocchi [7] used the Generalized Differential Quadrature method to study the free vibration of several laminated composite doubly-curved shells, singly-curved shells and plates with continuous thickness variation.

The cracks may appear in the plate at the manufacturing stage or in the process of exploitation and use. The stiffness of the plate is then greatly reduced. The theories of research on cracks have been studied by many scientists. Recently, phase field theory has been used to simulate the state of cracks. Using the phase field theory, Phuc et al. [9] studied the stability of cracked rectangular plate with variable thickness, Duc et al. [10] determined free vibration and buckling of cracked Mindlin plates, Phuc et al. [11] analyzed the effect of cracks on the stability of the functionally graded plates with variable-thickness, Phuc [12] investigated the free vibration of the functionally graded material cracked plates with varying thickness.

According to the author's knowledge, there are no researches on the free vibration of multi-cracked plates with variable thickness, the plates are made of homogeneous material. The survey affects of the aspect ratio of the plate; the length, angle, position and number of cracks on free vibration frequency are also investigated.

\section{BASIC EQUATIONS}

\subsection{Plate theoretical model}

According to the new simple third-order shear deformation plate theory of Shi [13] for harmonic motion, the displacement field is taken as

$$
\begin{aligned}
& u_{1}(x, y, z, t)=u_{0}(x, y, t)+\frac{5}{4}\left(z-\frac{4}{3 h^{2}(x)} z^{3}\right) \varphi_{x}(x, y, t)+\left(\frac{1}{4} z-\frac{5}{3 h^{2}(x)} z^{3}\right) w_{0, x} \\
& u_{2}(x, y, z, t)=v_{0}(x, y, t)+\frac{5}{4}\left(z-\frac{4}{3 h^{2}(x)} z^{3}\right) \varphi_{y}(x, y, t)+\left(\frac{1}{4} z-\frac{5}{3 h^{2}(x)} z^{3}\right) w_{0, y} \\
& u_{3}(x, y, z, t)=w(x, y, t)
\end{aligned}
$$

Where $u_{1}, u_{2}, u_{3}$ are represents the displacements at the mid-plane of the plate in the $x, y, z$ directions, respectively. While $\varphi_{x}, \varphi_{y}$ are the transverse normal rotations of the $x$ and $y$ axes.

Since the plate thickness varies along the x-axis with the function $h(x)$, the strains related 
to displacements in equation (1) can be rewritten as

$$
\left\{\begin{array}{l}
\varepsilon_{x} \\
\varepsilon_{y} \\
\varepsilon_{x y} \\
\gamma_{y z} \\
\gamma_{x z}
\end{array}\right\}=\left\{\begin{array}{l}
u_{0, x}+z \frac{1}{4}\left(5 \varphi_{x, x}+w_{, x x}\right)+z^{3}\left(\frac{-5}{3 h^{2}}\right)\left[\varphi_{x, x}+w_{, x x}+\left(\frac{-2}{h}\right) h_{, x}\left(\varphi_{x}+w_{, x}\right)\right] \\
v_{0, y}+z \frac{1}{4}\left(5 \varphi_{y, y}+w_{, y y}\right)+z^{3}\left(\frac{-5}{3 h^{2}}\right)\left(\varphi_{y, y}+w_{, y y}\right) \\
u_{0, y}+v_{0, x}+z \frac{1}{4}\left(5 \varphi_{x, y}+2 w_{, x y}+5 \varphi_{y, x}\right)+ \\
\quad+z^{3}\left(\frac{-5}{3 h^{2}}\right)\left[\varphi_{x, y}+2 w_{, x y}+\varphi_{y, x}+\left(\frac{-2}{h}\right) h_{, x}\left(\varphi_{y}+w_{, y}\right)\right] \\
\frac{5}{4}\left(\varphi_{y}+w_{, y}\right)+z^{2}\left(\frac{-5}{h^{2}}\right)\left(\varphi_{y}+w_{, y}\right) \\
\frac{5}{4}\left(\varphi_{x}+w_{, x}\right)+z^{2}\left(\frac{-5}{h^{2}}\right)\left(\varphi_{x}+w_{, x}\right)
\end{array}\right\}
$$

The relationship of the normal and shear stress with respect to the strains and shear components in the plate, which is constrained by linear elasticity theory, is given by:

$$
\begin{gathered}
\left\{\begin{array}{l}
\boldsymbol{\sigma}=\boldsymbol{D}_{m}\left(\boldsymbol{\varepsilon}^{(0)}+z \boldsymbol{\varepsilon}^{(1)}+z^{3} \boldsymbol{\varepsilon}^{(3)}\right) \\
\boldsymbol{\tau}=\boldsymbol{D}_{s}\left(\boldsymbol{\gamma}^{(0)}+z^{2} \boldsymbol{\gamma}^{(2)}\right)
\end{array}\right. \\
\text { With } \boldsymbol{\sigma}=\left[\begin{array}{lll}
\sigma_{x} & \sigma_{y} & \sigma_{x y}
\end{array}\right]^{T} \text { and } \boldsymbol{\tau}=\left[\begin{array}{ll}
\tau_{y z} & \tau_{x z}
\end{array}\right]^{T} \\
\boldsymbol{D}_{m}=\frac{E}{1-v^{2}}\left[\begin{array}{ccc}
1 & v & 0 \\
v & 1 & 0 \\
0 & 0 & \frac{1}{2}(1-v)
\end{array}\right] ; \quad \boldsymbol{D}_{s}=\frac{E}{2(1+v)}\left[\begin{array}{cc}
1 & 0 \\
0 & 1
\end{array}\right]
\end{gathered}
$$

It should be noted that equation (3) are denoted $\boldsymbol{\varepsilon}^{(0)} ; \boldsymbol{\varepsilon}^{(1)} ; \boldsymbol{\varepsilon}^{(3)} ; \boldsymbol{\gamma}^{(0)} ; \boldsymbol{\gamma}^{(2)}$ for the strain and shear components induced from equations (2) of the displacements in the plate [13].

The normal forces, bending moments, higher order moments and shear forces can be computed and written through the following equations:

$$
\left\{\begin{array}{c}
\widehat{\boldsymbol{N}} \\
\widehat{\boldsymbol{M}} \\
\widehat{\boldsymbol{P}} \\
\widehat{\boldsymbol{Q}} \\
\widehat{\boldsymbol{R}}
\end{array}\right\}=\left[\begin{array}{ccccc}
\boldsymbol{A} & \boldsymbol{B} & \boldsymbol{E} & 0 & 0 \\
\boldsymbol{B} & \boldsymbol{D} & \boldsymbol{F} & 0 & 0 \\
\boldsymbol{E} & \boldsymbol{F} & \boldsymbol{H} & 0 & 0 \\
0 & 0 & 0 & \overline{\boldsymbol{A}} & \overline{\boldsymbol{B}} \\
0 & 0 & 0 & \overline{\boldsymbol{B}} & \overline{\boldsymbol{D}}
\end{array}\right]\left\{\begin{array}{l}
\boldsymbol{\varepsilon}^{(0)} \\
\boldsymbol{\varepsilon}^{(1)} \\
\boldsymbol{\varepsilon}^{(3)} \\
\boldsymbol{\gamma}^{(0)} \\
\boldsymbol{\gamma}^{(2)}
\end{array}\right\}
$$


Where $(\boldsymbol{A}, \boldsymbol{B}, \boldsymbol{D}, \boldsymbol{E}, \boldsymbol{F}, \boldsymbol{H})=\int_{-h / 2}^{h / 2}\left(1, z, z^{2}, z^{3}, z^{4}, z^{6}\right) \boldsymbol{D}_{m} d z$

$$
(\overline{\boldsymbol{A}}, \overline{\boldsymbol{B}}, \overline{\boldsymbol{D}})=\int_{-h / 2}^{h / 2}\left(1, z^{2}, z^{4}\right) \boldsymbol{D}_{s} d z
$$

According to the theory of elasticity, strain energy $U$ for plate can be given by:

$$
U(\boldsymbol{d})=\frac{1}{2} \int_{\Omega}\left(\begin{array}{l}
\boldsymbol{\varepsilon}^{(0) T} \boldsymbol{A} \boldsymbol{\varepsilon}^{(0)}+\boldsymbol{\varepsilon}^{(0) T} \boldsymbol{B} \boldsymbol{\varepsilon}^{(1)}+\boldsymbol{\varepsilon}^{(0) T} \boldsymbol{E} \boldsymbol{\varepsilon}^{(3)}+ \\
+\boldsymbol{\varepsilon}^{(1) T} \boldsymbol{B} \boldsymbol{\varepsilon}^{(0)}+\boldsymbol{\varepsilon}^{(1) T} \boldsymbol{D} \boldsymbol{\varepsilon}^{(1)}+\boldsymbol{\varepsilon}^{(1) T} \boldsymbol{F} \boldsymbol{\varepsilon}^{(3)}+ \\
+\boldsymbol{\varepsilon}^{(3) T} \boldsymbol{E} \boldsymbol{\varepsilon}^{(0)}+\boldsymbol{\varepsilon}^{(3) T} \boldsymbol{F} \boldsymbol{\varepsilon}^{(1)}+\boldsymbol{\varepsilon}^{(3) T} \boldsymbol{H} \boldsymbol{\varepsilon}^{(3)}+ \\
+\boldsymbol{\gamma}^{(0) T} \overline{\boldsymbol{A}} \boldsymbol{\gamma}^{(0)}+\boldsymbol{\gamma}^{(0) T} \bar{B} \boldsymbol{\gamma}^{(2)}+\boldsymbol{\gamma}^{(2) \mathrm{T}} \overline{\boldsymbol{B}} \boldsymbol{\gamma}^{(0)}+\boldsymbol{\gamma}^{(2) \mathrm{T}} \overline{\boldsymbol{D}} \boldsymbol{\gamma}^{(2)}
\end{array}\right) d \Omega
$$

\subsection{Crack modeling and phase field theory}

In the phase field theory of fracture mechanics [9-12], the state of the material is represented by the field variable $s$, which is 0 if there is a crack and 1 if the material is undamaged. With $s$ is in the range of 0 to 1 , the material is in a softening state, which is the transition state of the material between the normal state and the cracked state. Hence, $s$ can be considered as a damage parameter in elastic damage models. This parameter $s$ is considered a variable in the functional energy formula by $s^{2}$, so cracks in the plate can occur when the deformation energy is decreased.

When the plate is cracked, the total strain energy of plate due to the normal forces, bending moments, higher order moments and shear forces could be written as

$$
\begin{aligned}
& U(\boldsymbol{d}, s)=\left\{\begin{array}{l}
\frac{1}{2} \int_{\Omega} s^{2}\left(\begin{array}{l}
\boldsymbol{\varepsilon}^{(0) T} \boldsymbol{A} \boldsymbol{\varepsilon}^{(0)}+\boldsymbol{\varepsilon}^{(0) T} \boldsymbol{B} \boldsymbol{\varepsilon}^{(1)}+\boldsymbol{\varepsilon}^{(0) T} \boldsymbol{E} \boldsymbol{\varepsilon}^{(3)}+ \\
+\boldsymbol{\varepsilon}^{(1) T} \boldsymbol{B} \boldsymbol{\varepsilon}^{(0)}+\boldsymbol{\varepsilon}^{(1) T} \boldsymbol{D} \boldsymbol{\varepsilon}^{(1)}+\boldsymbol{\varepsilon}^{(1) T} \boldsymbol{F} \boldsymbol{\varepsilon}^{(3)}+ \\
+\boldsymbol{\varepsilon}^{(0) T} \overline{\boldsymbol{A}} \boldsymbol{\gamma}^{(0)}+\boldsymbol{\varepsilon}^{(0) T} \overline{\boldsymbol{F}} \boldsymbol{\varepsilon}^{(1)}+\boldsymbol{\varepsilon}^{(3) T} \boldsymbol{H} \boldsymbol{\varepsilon}^{(3)}+\boldsymbol{\gamma}^{(2) \mathrm{T}} \overline{\boldsymbol{B}} \boldsymbol{\gamma}^{(0)}+\boldsymbol{\gamma}^{(2) \mathrm{T}} \overline{\boldsymbol{D}} \boldsymbol{\gamma}^{(2)}
\end{array}\right) d \Omega \\
+\int_{\Omega} G_{C} h\left[\frac{(1-s)^{2}}{4 l}+l|\nabla s|^{2}\right] d \Omega
\end{array}\right\} \\
& \Rightarrow \quad U(\boldsymbol{d}, s)=\left\{\int_{\Omega} s^{2} \boldsymbol{\Psi}(\boldsymbol{d}) d \Omega+\int_{\Omega} G_{C} h\left[\frac{(1-s)^{2}}{4 l}+l|\nabla s|^{2}\right] d \Omega\right\}
\end{aligned}
$$

where $d$ is used to denote the displacement vector, and $G_{C}$ is used for the critical energy release rate in Griffith's theory and $l$ is a positive regularization constant to adjust the size of the fracture zone. 
Transport and Communications Science Journal, Vol. 71, Issue 7 (09/2020/), 853-867

The kinetic energy of the plate:

$$
T(\boldsymbol{d}, s)=\frac{1}{2} \int s^{2}\left\{\begin{array}{c}
T(\boldsymbol{d}, s)=\frac{1}{2} \int_{V} s^{2} \rho\left(\dot{u}_{1}^{2}+\dot{u}_{2}^{2}+\dot{u}_{3}^{2}\right) d V \\
\left.-\frac{10}{16}\left[\dot{w}_{, x}^{2}+25\left(\dot{\varphi}_{x}^{2}+\dot{\varphi}_{y}^{2}\right)+10\left(\dot{\varphi}_{x} \dot{w}_{, x}+\dot{\varphi}_{y} \dot{w}_{, y}\right)+\dot{w}_{, y}^{2}\right] \dot{u}_{0}^{2} \dot{w}_{, x}+\dot{v}_{0}^{2} \dot{\varphi}_{y}+\dot{v}_{0} \dot{w}_{, y}\right) I_{3} \\
\left.-\frac{10}{12 h^{2}}\left[\dot{w}_{, x}^{2}+5\left(\dot{\varphi}_{x}^{2}+\dot{\varphi}_{y}^{2}\right)+6\left(\dot{\varphi}_{x} \dot{w}_{, x}+\dot{\varphi}_{y} \dot{w}_{, y}\right)+\dot{\varphi}_{, y}^{2}\right] \dot{u}_{0} \dot{w}_{, x}+\dot{v}_{0} \dot{w}_{, \mathrm{y}}\right] I_{1} \\
+\frac{25}{9 h^{4}}\left[\dot{w}_{, x}^{2}+\dot{\varphi}_{x}^{2}+2\left(\dot{\varphi}_{x} \dot{w}_{, x}+\dot{\varphi}_{y} \dot{w}_{, y}\right)+\dot{\varphi}_{y}^{2}+\dot{w}_{, y}^{2}\right] I_{6}
\end{array}\right\} d \Omega
$$

where

$$
I_{i}=\int_{-h / 2}^{h / 2} \rho z^{i} d z ; i=0,1,2,3,4,6
$$

Based on the above expression, the Lagrangian function for plates can be expressed as follows:

$$
\begin{aligned}
& L(\boldsymbol{d}, s)=T(\boldsymbol{d}, s)-U(\boldsymbol{d}, s) \\
& =\left\{\int_{\Omega} s^{2} \Gamma(\boldsymbol{d}) d \boldsymbol{\Omega}-\int_{\Omega} G_{C} h\left[\frac{(1-s)^{2}}{4 l}+l|\nabla s|^{2}\right] d \boldsymbol{\Omega}\right\}
\end{aligned}
$$

The first variation of the functional $L(\boldsymbol{d}, s)$ is particularly computed by

$$
\left\{\begin{array}{l}
\delta L(\boldsymbol{d}, s, \delta \boldsymbol{d})=0 \\
\delta L(\boldsymbol{d}, s, \delta s)=0
\end{array}\right.
$$

Continuously, eigenvalue and shape functions are given by the equation:

$$
\left\{\begin{array}{l}
\left(\sum \mathbf{K}^{e}+\boldsymbol{\omega}^{2} \sum \boldsymbol{M}^{e}\right) \boldsymbol{d}=0 \\
\int_{\Omega} 2 s \Gamma(\boldsymbol{d}) \boldsymbol{\delta} s d \boldsymbol{\Omega}-\int_{\Omega} 2 G_{C} h\left[-\frac{(1-s) \boldsymbol{\delta} s}{4 l}+l \nabla s \nabla(\boldsymbol{\delta} s)\right] d \mathbf{\Omega}=0
\end{array}\right.
$$

After calculating the value $s$ from equation (15), it is easy to calculate the free vibration frequency of the plate in equation (14). 
Transport and Communications Science Journal, Vol. 71, Issue 7 (09/2020), 853-867

\section{NUMBERICAL RESULTS AND DISCUSSION}

\subsection{Verification}

\subsubsection{Comparison of the free vibration of rectangular plates with the thickness varying according to the first order function}

In this section, the free vibration of homogeneous plates is studied and compared to Shufrin [3]. The properties of the plate are: $L=H=0.5 m, E=70 G P a, v=0.3$, $\rho=2700 \mathrm{~kg} / \mathrm{m}^{3}$. The plate thickness varies according to the first-order function $h=h_{0}(1-\alpha x / L)$ with $\alpha=\left(h_{0}-h_{a}\right) / h_{0}$. The plates are described by a symbolism defining the boundary conditions at their edges starting from $x=0$ to $x=L, y=0, y=H$. For example, SSCF denotes a plate with simply supported edges at $x=0$ and $x=L$, clamped at $y=0$, and free at $y=H$. The formula to determine the free vibration frequency parameter of the plate can be written as [3]:

$$
\bar{\omega}=\omega H^{2} \sqrt{\rho h_{0} / D_{0}} / \pi^{2} \text { where } D_{0}=E h_{0}^{3} /\left(12\left(1-v^{2}\right)\right) .
$$

Table 1. The free vibration frequency factor for homogeneous plate with the first-order varying thickness.

\begin{tabular}{lllll}
\hline \hline BC & $h o / L$ & Shufrin [3] & Phuc [12] & Present \\
\hline \multirow{3}{*}{ SSSS } & 0.1 & 1.4504 & 1.45041 & 1.45029 \\
\cline { 2 - 5 } & 0.2 & 1.3738 & 1.37381 & 1.37343 \\
\cline { 2 - 5 } & 0.4 & 1.1664 & 1.16645 & 1.16557 \\
\hline \multirow{3}{*}{ SSFF } & 0.1 & 0.7201 & 0.72019 & 0.720108 \\
\cline { 2 - 5 } & 0.2 & 0.6999 & 0.69996 & 0.699842 \\
\hline \hline
\end{tabular}

\subsubsection{Comparison of free vibration of cracked plates}

In this section, the free vibration of cracked homogeneous plates is studied. The properties of plate same as section 3.1.1. The crack length ratios as $c / L=0.1,0.2,0.3,0.4,0.5,0.6$ were investigated to examine the convergence of the presented method. The formula to determine the free vibration frequency parameter of the plate is defined as [8]:

$$
\bar{\omega}=\omega H^{2} \sqrt{\rho h / D} \text { where } D=E h^{3} /\left(12\left(1-v^{2}\right)\right)
$$


Transport and Communications Science Journal, Vol. 71, Issue 7 (09/2020/), 853-867

Table 2. The free vibration frequency parameter of cracked plates with constant thickness.

\begin{tabular}{|c|c|c|c|c|c|c|}
\hline \multirow{2}{*}{$c / L$} & \multirow{2}{*}{ Source } & \multicolumn{5}{|c|}{ Mode } \\
\hline & & 1 & 2 & 3 & 4 & 5 \\
\hline \multirow{2}{*}{0.1} & Huang et al. [8] & 19.66 & 49.34 & 49.35 & 78.96 & 97.79 \\
\hline & Present & 19.5875 & 49.2907 & 49.2909 & 78.7505 & 96.9168 \\
\hline \multirow{2}{*}{0.2} & Huang et al. [8] & 19.33 & 49.19 & 49.32 & 78.95 & 94.13 \\
\hline & Present & 19.2408 & 49.0522 & 49.2695 & 78.6747 & 93.396 \\
\hline \multirow{2}{*}{0.3} & Huang et al. [8] & 18.85 & 48.5 & 49.24 & 78.89 & 89.73 \\
\hline & Present & 18.7537 & 48.2213 & 49.1636 & 78.5378 & 89.2382 \\
\hline \multirow{2}{*}{0.4} & Huang et al. [8] & 18.29 & 46.65 & 49.03 & 78.61 & 85.56 \\
\hline & Present & 18.1988 & 46.3424 & 48.9381 & 78.1554 & 85.4286 \\
\hline \multirow{2}{*}{0.5} & Huang et al. [8] & 17.72 & 43.06 & 48.69 & 77.72 & 82.18 \\
\hline & Present & 17.643 & 43.3373 & 48.5765 & 77.1341 & 82.3518 \\
\hline \multirow{2}{*}{0.6} & Huang et al. [8] & 17.19 & 37.99 & 48.22 & 75.59 & 79.6 \\
\hline & Present & 17.1395 & 39.8011 & 48.1085 & 74.9304 & 80.0119 \\
\hline
\end{tabular}

As can be seen from sections 3.1.1 and 3.1.2, the calculation results are very close to the comparison articles. Here, in Tables 1 and 2, to ensure the convergence program, the finite element number of the square plate is divided as 20x20 elements. Therefore, we develop a calculation program based on the code of those sections to calculate the free vibration frequencies of the cracked plates with varying thickness in section 3.2 below.

\subsection{Free vibration analysis of cracked homogeneous plates with varying thickness}

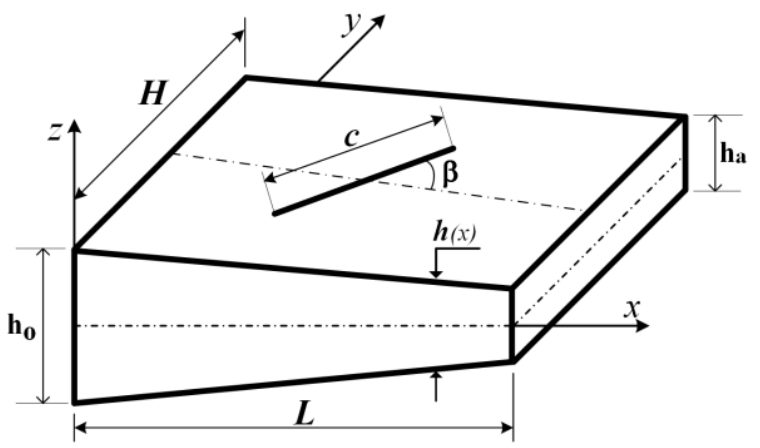

a) The plate with a crack

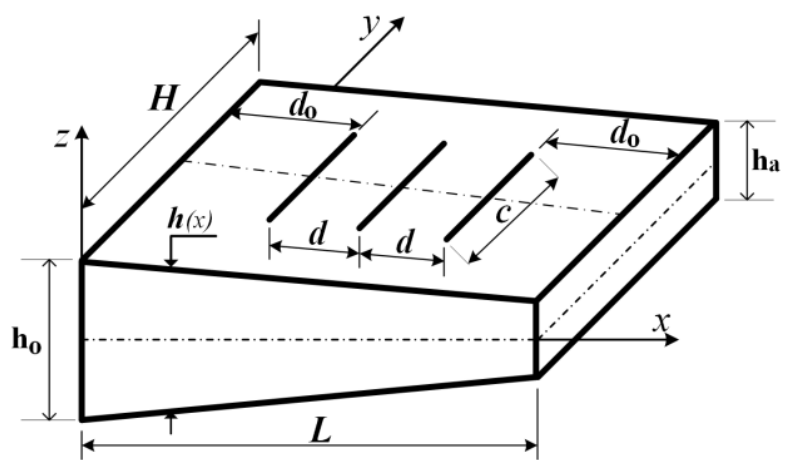

b) The multi-cracked plate

Figure 1 . Geometry of cracked plate with varying thickness according to the first-oder function.

Based on the theories and comparisons of above sections, the cracked rectangular plates are presented in this section. The plates have one or more cracks (as shown in Fig. 1). The 
Transport and Communications Science Journal, Vol. 71, Issue 7 (09/2020), 853-867

thickness of plates is according to the first-order function with and the ratio of the crack length $(c / L)$ is varying from 0.1 to 0.7 ; the properties of plates are provided in section 3.1.1. At the edges of the plate, the boundary condition is full simple support (SSSS). The nondimensional free vibration frequency of the plates is defined by Eq. (16).

Table 3. The free vibration frequency parameters of cracked plates with $\mathrm{L}=\mathrm{H}=0.5 \mathrm{~m} ; \mathrm{h}_{0}=0.025 \mathrm{~m} ; \mathrm{h}_{\mathrm{a}}=\mathrm{h}_{0} / 2$ and SSSS.

\begin{tabular}{|c|c|c|c|c|c|c|}
\hline \multirow{2}{*}{$c / L$} & \multirow{2}{*}{$\begin{array}{l}\text { Inclined } \\
\text { crack }(\beta)\end{array}$} & \multicolumn{5}{|c|}{ Mode } \\
\hline & & 1 & 2 & 3 & 4 & 5 \\
\hline 0 & - & 1.47224 & 3.59279 & 3.63005 & 5.78802 & 6.92957 \\
\hline \multirow{7}{*}{0.2} & $0^{0}$ & 1.43401 & 3.56406 & 3.6209 & 5.75805 & 6.63099 \\
\hline & $15^{0}$ & 1.4342 & 3.56295 & 3.61947 & 5.7506 & 6.65452 \\
\hline & $30^{0}$ & 1.43482 & 3.56075 & 3.61538 & 5.73714 & 6.70905 \\
\hline & $45^{0}$ & 1.43604 & 3.56012 & 3.60921 & 5.73268 & 6.76311 \\
\hline & $60^{\circ}$ & 1.43754 & 3.60158 & 3.56303 & 5.7425 & 6.79087 \\
\hline & $75^{0}$ & 1.44051 & 3.57369 & 3.59398 & 3.75886 & 6.80685 \\
\hline & $90^{\circ}$ & 1.43938 & 3.58789 & 3.57195 & 5.76517 & 6.78172 \\
\hline \multirow{7}{*}{0.4} & $0^{0}$ & 1.35719 & 3.31802 & 3.59063 & 5.6159 & 6.11886 \\
\hline & $15^{0}$ & 1.35605 & 3.31291 & 3.58742 & 5.5613 & 6.22099 \\
\hline & $30^{0}$ & 1.35434 & 3.30255 & 3.57927 & 5.49011 & 6.39549 \\
\hline & $45^{0}$ & 1.35565 & 3.29813 & 3.57134 & 5.47624 & 6.46517 \\
\hline & $60^{\circ}$ & 1.36106 & 3.30991 & 3.56764 & 5.53235 & 6.36044 \\
\hline & $75^{0}$ & 1.37631 & 3.44598 & 3.56876 & 5.66773 & 6.38494 \\
\hline & $90^{\circ}$ & 1.3696 & 3.2977 & 3.56679 & 5.69252 & 6.03496 \\
\hline \multirow{7}{*}{0.6} & $0^{0}$ & 1.28081 & 2.65944 & 3.52979 & 5.21767 & 5.73978 \\
\hline & $15^{0}$ & 1.27456 & 2.66753 & 3.5175 & 5.13433 & 5.86067 \\
\hline & $30^{0}$ & 1.2619 & 2.66678 & 3.48855 & 5.00535 & 6.05457 \\
\hline & $45^{0}$ & 1.25782 & 2.68542 & 3.46993 & 4.95243 & 6.14677 \\
\hline & $60^{0}$ & 1.27118 & 2.78237 & 3.48051 & 5.03414 & 5.9492 \\
\hline & $75^{0}$ & 1.32 & 3.34583 & 3.51283 & 5.50157 & 6.14798 \\
\hline & $90^{\circ}$ & 1.29284 & 2.67201 & 3.50712 & 5.14022 & 5.41946 \\
\hline
\end{tabular}


In Table 1, the effect of the crack length $(c / L)$ and the slope angle of the crack $(\beta)$ on the frequency of the vibration modes is different. With the increase of the cracked angle $\beta$ : While the vibration frequency in Mode 5 increases and then decreases, Modes 3 and 4 are opposite (decrease and then increase); in Modes 1 and 2, the frequency has no clear rule, Mode 1 increases and then decreases at $c / L=0.2$ but decreases and then increases at $c / L=0.4$ and $c / L=0.6$, Mode 2 decreases and then increases at $c / L=0.2$ and $c / L=0.4$ but increase and then decrease at $c / L=0.6$. We also found that the larger the ratio of crack length $(c / L)$, the lower the stiffness of the plate reduces the vibration frequency, which is also shown in Tables 4, 5, 6 and Fig. 2, 3.

Fig. 2 describes the first shape modes of central-cracked rectangular plate with changing thickness and cracked angle from $0^{0}$ to $90^{\circ}$.

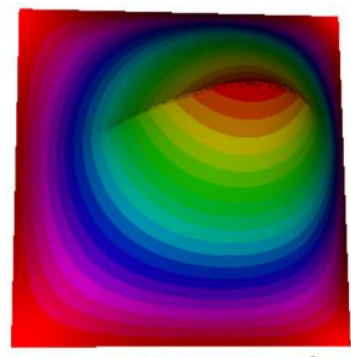

$\bar{\omega}=1.31696 ; \beta=0^{0}$

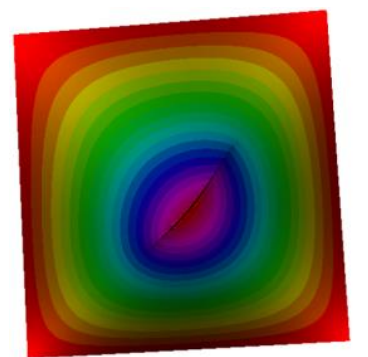

$\bar{\omega}=1.30763 ; \beta=45^{0}$

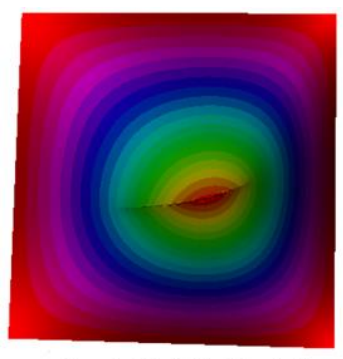

$\bar{\omega}=1.31405 ; \beta=15^{0}$
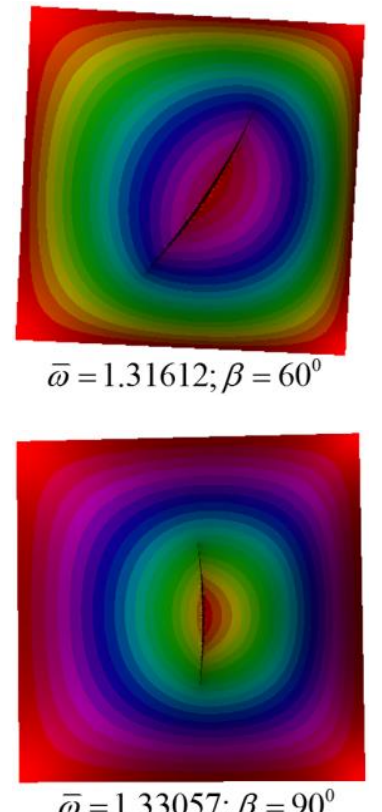

$\bar{\omega}=1.33057 ; \beta=90$

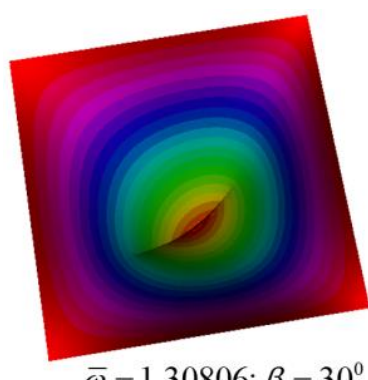

$\bar{\omega}=1.30806 ; \beta=30^{\circ}$

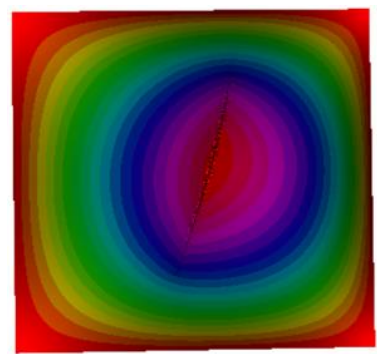

$\bar{\omega}=1.34349 ; \beta=75^{\circ}$

Figure 2. The first mode shapes of SSSS cracked plates with $\mathrm{L}=\mathrm{H}=0.5 \mathrm{~m} ; \mathrm{c} / \mathrm{L}=0.5 ; \mathrm{h}_{0}=0.025 \mathrm{~m} ; \mathrm{h}_{\mathrm{a}} / \mathrm{h}_{0}=0.50$.

Fig. 3 shows that the vibration frequency decreases as the aspect ratio of the plate $(L / H)$ increases. This is explained by the fact that when a constant edge $(H=0.5 \mathrm{~m})$ is made, the larger the $L / H$ is, the less the plate stiffness is reduced. The vibration frequency of the plate also decreases in proportion to the decrease in the thickness ratio $\left(h_{a} / h_{0}\right),\left(h_{a} / h_{0}\right.$ decreases corresponding to the increase of variable thickness ratio $\alpha$ ). 
Transport and Communications Science Journal, Vol. 71, Issue 7 (09/2020), 853-867
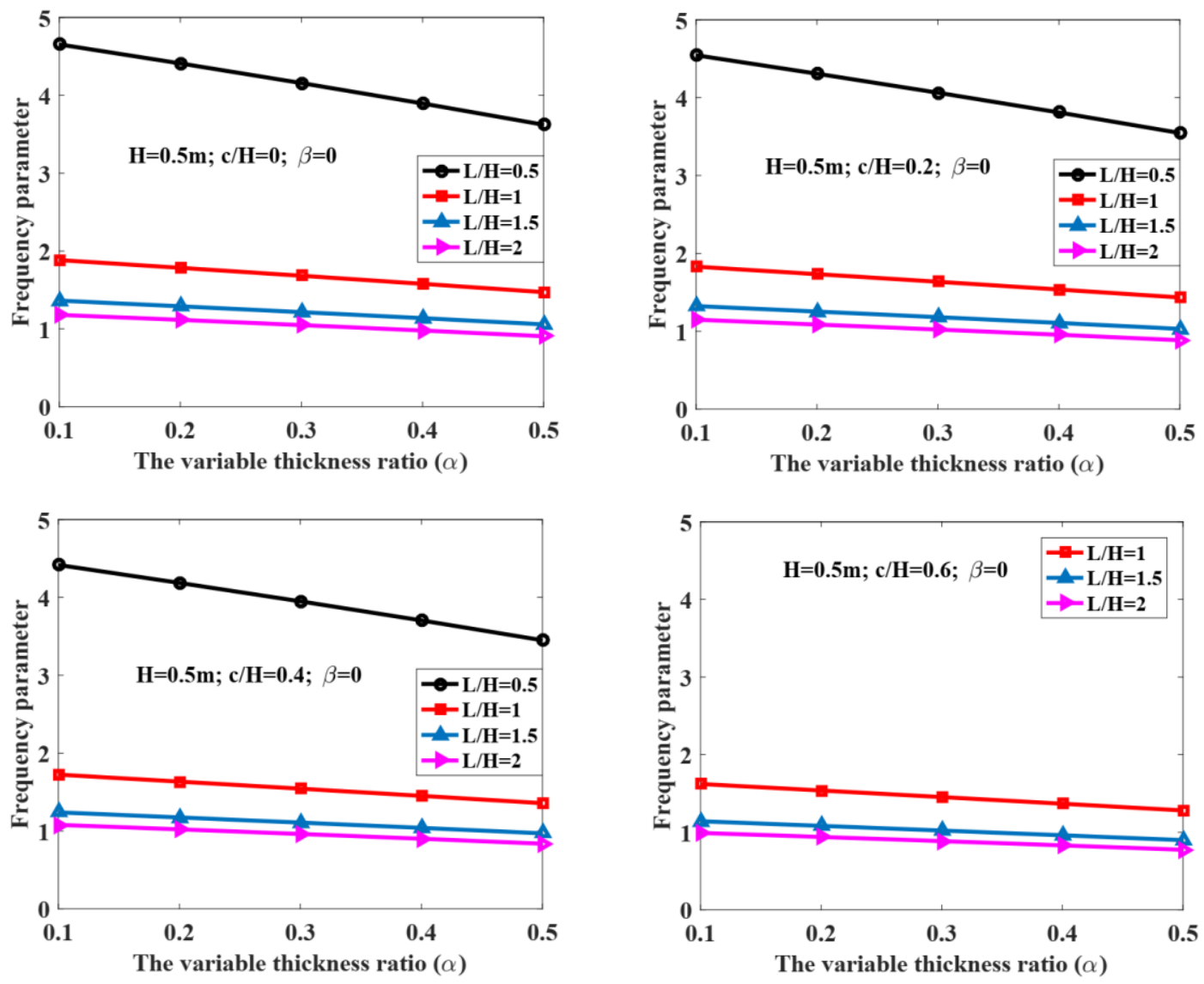

Figure 3. The frequency parameter of cracked plate with change of aspect ratio and thickness ratio.

Table 4 shows the first vibration frequency parameter of the cracked plate (one crack) with variable thickness and the edges of the plates are full single supported (SSSS) or fully clamped $(C C C C)$. It is clear that with full single supported boundary condition, the plate stiffness is smaller than the full clamped and therefore the frequency is also correspondingly smaller. The plate stiffness also decreases as the thickness ratios $\left(h_{0} / h_{a}\right)$ and the crack length ratio $(c / L)$ increase, causing the frequency to decrease accordingly.

Table 4 . The free vibration frequency parameter of cracked plates with different boundary conditions and $\mathrm{L}=\mathrm{H}=0.5 \mathrm{~m} ; \mathrm{h}_{0}=0.025 \mathrm{~m} ; \beta=0^{0}$.

\begin{tabular}{ccccccc}
\hline \hline \multirow{2}{*}{$\begin{array}{c}\text { Boundary } \\
\text { conditions }\end{array}$} & $h_{a} / h_{0}$ & \multicolumn{6}{c}{$c / L$} \\
\cline { 2 - 7 } & & 0 & 0.1 & 0.3 & 0.5 & 0.7 \\
\hline \multirow{4}{*}{ SSSS } & 0.9 & 1.88401 & 1.8671 & 1.77912 & 1.66969 & 1.5835 \\
\cline { 2 - 7 } & 0.8 & 1.78432 & 1.76857 & 1.68616 & 1.58311 & 1.50161 \\
\cline { 2 - 7 } & 0.7 & 1.68274 & 1.66827 & 1.59183 & 1.49561 & 1.41906 \\
\cline { 2 - 7 } & 0.6 & 1.5789 & 1.56582 & 1.49586 & 1.407 & 1.33573 \\
\hline \hline
\end{tabular}


Transport and Communications Science Journal, Vol. 71, Issue 7 (09/2020/), 853-867

\begin{tabular}{lllllll}
\hline \hline & 0.9 & 3.37417 & 3.34238 & 3.18261 & 3.02511 & 2.94805 \\
\cline { 2 - 7 } CCCC & 0.8 & 3.19799 & 3.16837 & 3.01837 & 2.86938 & 2.79585 \\
\cline { 2 - 7 } & 0.7 & 3.01501 & 2.98788 & 2.8488 & 2.709 & 2.63888 \\
\cline { 2 - 7 } & 0.6 & 2.82395 & 2.79966 & 2.67284 & 2.54308 & 2.47628 \\
\cline { 2 - 7 } & 0.5 & 2.62294 & 2.60189 & 2.48895 & 2.37033 & 2.30678 \\
\hline \hline
\end{tabular}

In tables 5 and 6 , the plate has three cracks parallel to the y-axis, the length of cracks $c$, spaced $d$ and apart from the edge $d_{0}$ (Fig. 1).

Table 5. The first frequency parameter of the plates with three cracks and $\mathrm{L}=\mathrm{H}=0.5 \mathrm{~m} ; \mathrm{h}_{0}=0.01 \mathrm{~m} ; \mathrm{SSSS}$.

\begin{tabular}{|c|c|c|c|c|c|c|}
\hline \multirow{2}{*}{$c / H$} & \multirow{2}{*}{$d / L$} & \multicolumn{5}{|c|}{$h_{a} / h_{0}$} \\
\hline & & 0.9 & 0.8 & 0.7 & 0.6 & 0.5 \\
\hline \multirow{4}{*}{0.2} & 0.1 & 1.80313 & 1.70814 & 1.61256 & 1.51618 & 1.41859 \\
\hline & 0.2 & 1.80006 & 1.70471 & 1.60827 & 1.51051 & 1.41103 \\
\hline & 0.3 & 1.81593 & 1.71913 & 1.62075 & 1.52044 & 1.41766 \\
\hline & 0.4 & 1.83352 & 1.73592 & 1.63685 & 1.5359 & 1.43236 \\
\hline \multirow{4}{*}{0.4} & 0.1 & 1.67085 & 1.58395 & 1.49732 & 1.41093 & 1.32465 \\
\hline & 0.2 & 1.64669 & 1.56012 & 1.47296 & 1.3851 & 1.29638 \\
\hline & 0.3 & 1.6561 & 1.5682 & 1.47888 & 1.38781 & 1.29453 \\
\hline & 0.4 & 1.68053 & 1.59167 & 1.50153 & 1.40963 & 1.31516 \\
\hline \multirow{4}{*}{0.6} & 0.1 & 1.55463 & 1.47374 & 1.39293 & 1.3122 & 1.23151 \\
\hline & 0.2 & 1.50052 & 1.42185 & 1.34239 & 1.26201 & 1.18059 \\
\hline & 0.3 & 1.47991 & 1.40201 & 1.32266 & 1.24156 & 1.15824 \\
\hline & 0.4 & 1.48806 & 1.41 & 1.33054 & 1.24926 & 1.16537 \\
\hline
\end{tabular}

We see that the first vibration mode of the plates occurs near the center of the plate (slightly skewed towards the thinner thickness as Fig. 2). Therefore, the more the cracks in the first mode occur, the lower the frequency is. In Table 5, with $d / L=0.2$ (at $c / H=0.2$ and $c / H=0.4$ ) and $d / L=0.3$ (at $c / H=0.6$ ), the plate with the lowest frequency where the cracks are concentrated (the cracks are located near where the first mode occurred). 
Transport and Communications Science Journal, Vol. 71, Issue 7 (09/2020), 853-867

Table 6. The first frequency parameter of multi-cracked plates with different boundary conditions and $\mathrm{L}=\mathrm{H}=0.5 \mathrm{~m} ; \mathrm{h}_{0}=\mathrm{H} / 50 ; \mathrm{c} / \mathrm{L}=0.50$.

\begin{tabular}{|c|c|c|c|c|c|c|}
\hline \multirow{2}{*}{$\begin{array}{l}\text { Boundary } \\
\text { conditions }\end{array}$} & \multirow{2}{*}{$d / L$} & \multicolumn{5}{|c|}{$h_{a} / h_{0}$} \\
\hline & & 0.9 & 0.8 & 0.7 & 0.6 & 0.5 \\
\hline \multirow{4}{*}{ SSFF } & 0.1 & 0.715312 & 0.676524 & 0.636443 & 0.594771 & 0.551069 \\
\hline & 0.2 & 0.703904 & 0.665488 & 0.625531 & 0.583696 & 0.539506 \\
\hline & 0.3 & 0.724817 & 0.685 & 0.64334 & 0.599424 & 0.552662 \\
\hline & 0.4 & 0.755852 & 0.714429 & 0.671157 & 0.625587 & 0.577036 \\
\hline \multirow{4}{*}{ CSFF } & 0.1 & 1.25969 & 1.21907 & 1.17665 & 1.13196 & 1.08424 \\
\hline & 0.2 & 1.21396 & 1.16738 & 1.11861 & 1.06728 & 1.0129 \\
\hline & 0.3 & 1.18137 & 1.13178 & 1.07995 & 1.02539 & 0.967431 \\
\hline & 0.4 & 1.15633 & 1.11055 & 1.06286 & 1.01262 & 0.958782 \\
\hline \multirow{4}{*}{$\mathrm{CCFF}$} & 0.1 & 1.84462 & 1.74572 & 1.64441 & 1.54023 & 1.43255 \\
\hline & 0.2 & 1.82632 & 1.72676 & 1.62286 & 1.51321 & 1.39727 \\
\hline & 0.3 & 1.73849 & 1.64598 & 1.55036 & 1.45078 & 1.34581 \\
\hline & 0.4 & 1.57965 & 1.49738 & 1.41404 & 1.32927 & 1.2423 \\
\hline
\end{tabular}

Table 6 describes the frequency parameters of multi-cracked plates with different boundary conditions. At the edges of the plates, the boundary conditions are described according to the following rule: The CSFF describes the clamped (C) and simply supported (S) boundary conditions in the y-direction and the free $(\mathrm{F})$ boundary conditions in the $\mathrm{x}$ direction. We find that the plates with CCFF boundary conditions have the largest stiffness, so its vibration frequency is also the largest. In contrast, the plates with SSFF boundary conditions have the smallest frequency. That is understandable, because the bound of the clamped boundary condition (C) is stronger than the simple supported (S) and the free boundary condition $(\mathrm{F})$ has no binding of edges.

Fig. 4 describes the first five vibration mode shapes of multi-cracked rectangular plate with changing the thickness along the length of the plate and different boundary conditions. 
Transport and Communications Science Journal, Vol. 71, Issue 7 (09/2020/), 853-867

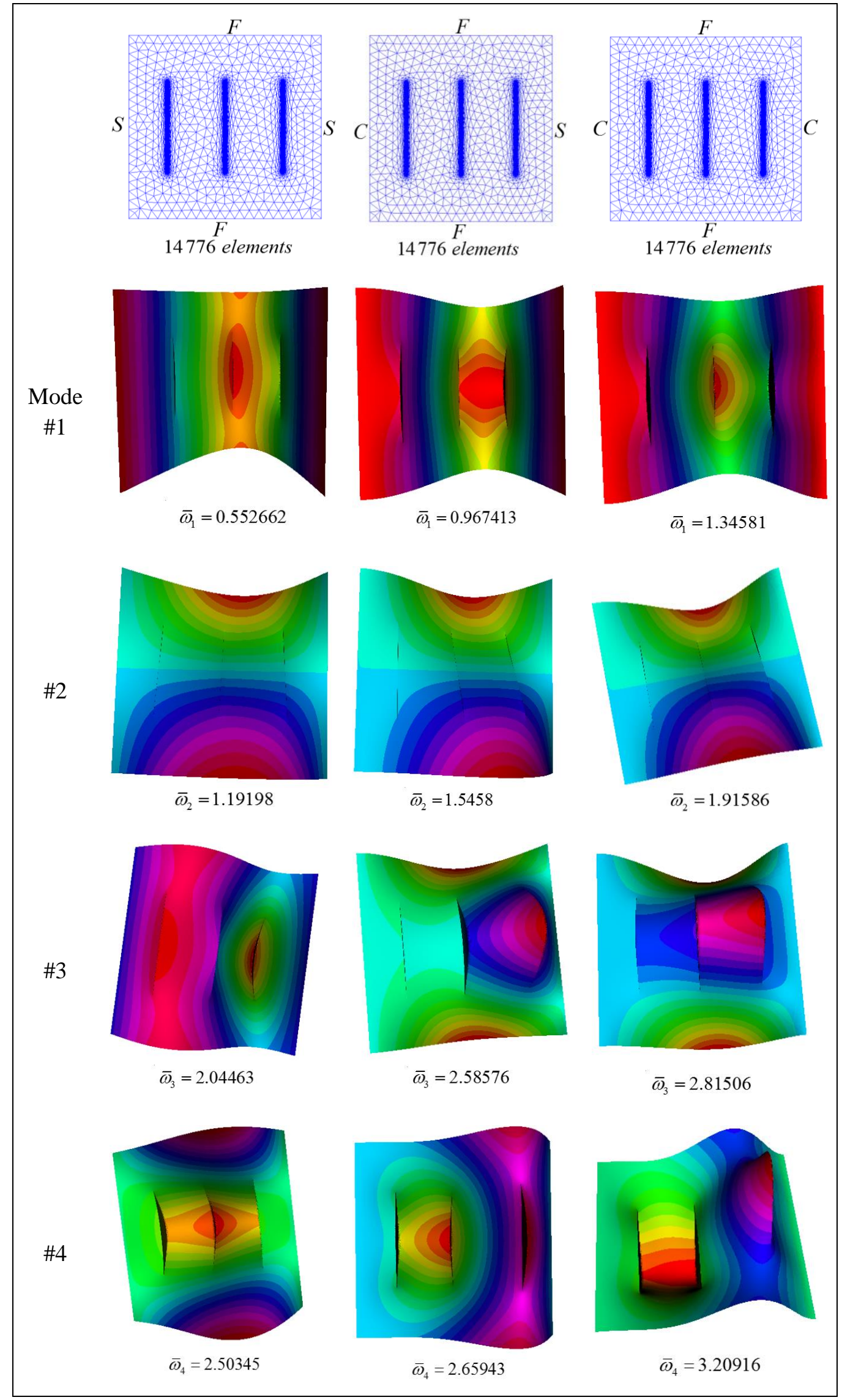




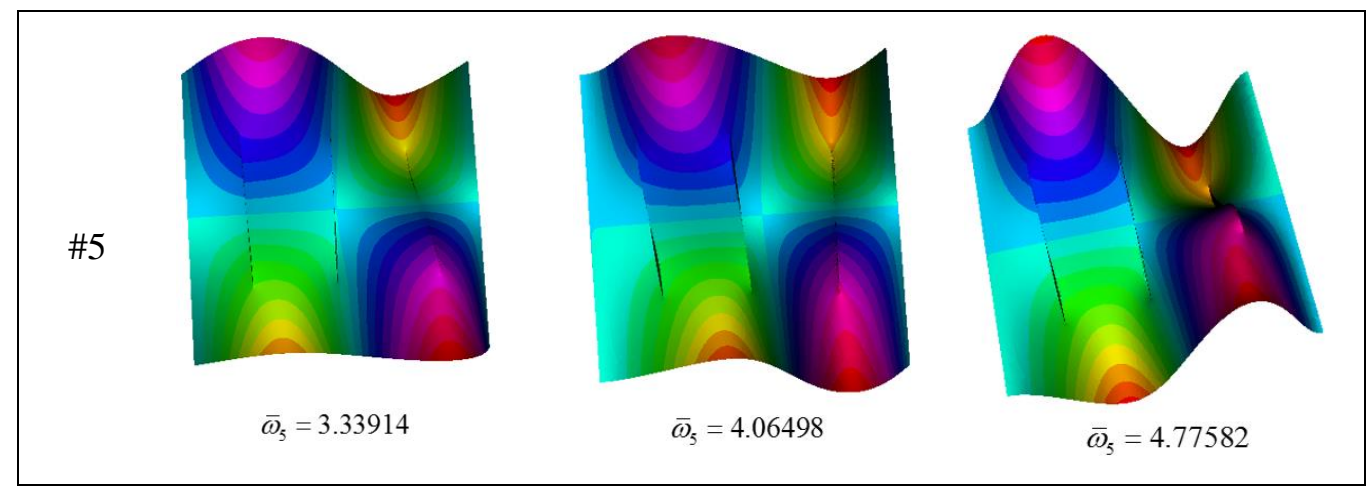

Figure 4. The first five mode shapes of multi-cracked plates with different boundary conditions and $\mathrm{L}=\mathrm{H}=0.5 \mathrm{~m} ; \mathrm{h}_{0}=0.01 \mathrm{~m} ; \mathrm{h}_{\mathrm{a}} / \mathrm{h}_{0}=0.5 ; \mathrm{c} / \mathrm{H}=0.5 ; \mathrm{d} / \mathrm{L}=0.30$.

\section{CONCLUSIONS}

This paper is based on the new third-order shear deformation theory, phase field theory and finite element method to calculate the vibration frequency parameters of cracked homogeneous plates with the varying thickness. From the detailed numerical results, the following can be concluded:

$>$ The length and number of cracks increase which increases the flexibility in the plate and hence the frequency decreases.

$>$ As the slope of the crack increases, the frequencies can decrease or increase.

$>$ The ratio between the two edges of the plate increases, leading to reduction stiffness of plate, so the vibration frequency decreases.

$>$ The smaller the thickness ratio $\left(h_{a} / h_{0}\right)$ is, the smaller the frequency is. Especially with the effect of simultaneous increase of $L / H, c / L$ and $h_{0} / h_{a}$ the plate stiffness decreases more, so the vibration frequency decreases rapidly.

$>$ The plate with the clamped boundary conditions have a greater stiffness than the simply supported plate or free plate and the corresponding frequencies is also greater.

This result will open new potential research of free vibration plates with the propagation of cracks.

\section{ACKNOWLEDGMENT}

This research is funded by University of Transport and Communications (UTC) under grant number T2020-CB-006.

\section{REFERENCES}

[1]. T. Sakiyama, M. Huang, Free vibration analysis of retangular plates with variable thickness, Journal of Sound and Vibration, 216 (1998) 268-286. https://doi.org/10.1006/jsvi.1998.1732

[2]. P. Malekzadeh, G. Karami, Polynomial and harmonic differential quadrature methods for free vibration of variable thickness thick skew plates, Engineering Structures, 27 (2005) 1563-1574. 
Transport and Communications Science Journal, Vol. 71, Issue 7 (09/2020/), 853-867

https://doi.org/10.1016/j.engstruct.2005.03.017

[3]. I. Shufrin , M. Eisenberger, Vibration of shear deformable plates with variable thickness - first-

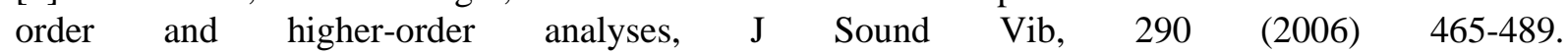
https://doi.org/10.1016/j.jsv.2005.04.003

[4]. U.S. Gupta, R. Lal, Seema Sharma, Vibration of non-homogeneous circular Mindlin plates with variable thickness, Journal of Sound and Vibration, 302 (2007) 1-17. https://doi.org/10.1016/j.jsv.2006.07.005

[5]. E. Efraim, M. Eisenberger, Exact vibration analysis of variable thickness thick annular isotropic and FGM plates, Journal of Sound and Vibration, 299 (2007) 720-738. https://doi.org/10.1016/j.jsv.2006.06.068

[6]. V. Tajeddini, A. Ohadi, M. Sadighi, Three-dimensional free vibration of variable thickness thick circular and annular isotropic and functionally graded plates on Pasternak foundation, International Journal of Mechanical Sciences, 53 (2011) 300-308. https://doi.org/10.1016/j.ijmecsci.2011.01.011

[7]. M. Bacciocchi, M. Eisenberger, N. Fantuzzi, F. Tornabene, E. Viola, Vibration analysis of variable thickness plates and shells by the generalized differential quadrature method, Composite Structures, 156 (2016) 218-237. https://doi.org/10.1016/j.compstruct.2015.12.004

[8]. C.S. Huang, A.W. Leissa, C.W. Chan, Vibrations of rectangular plates with internal cracks or slits, International Journal of Mechanical Sciences, 53 (2011) 436-445. https://doi.org/10.1016/j.ijmecsci.2011.03.006

[9]. P.M. Pham, D.V.Thom, D.H. Duc, N.D. Duc, The stability of cracked rectangular plate with variable thickness using phase field method, Thin-Walled Structures, 129 (2018) 157-165. https://doi.org/10.1016/j.tws.2018.03.028

[10].H.D. Duc, V.D. Thom, P.M. Pham, N.D. Duc, Validation simulation for free vibration and buckling of cracked Mindlin plates using phase-field method, Mech Adv Mater Struct, 26 (2018) 1018-1027. https://doi.org/10.1080/15376494.2018.1430262

[11].P.M. Pham, N.D. Duc, The effect of cracks on the stability of the functionally graded plates with variable-thickness using HSDT and phase-field theory, Composites Part B: Engineering, 175 (2019) 107086. https://doi.org/10.1016/j.compositesb.2019.107086

[12].P. M. Pham, Anynasys free vibration of the functionally graded material cracked plates with varying thickness using the phase-field theory, Transport and Communications Science Journal, 70 (2019) 122-131. (in Vietnamese) https://doi.org/10.25073/tcsj.70.2.35

[13].G. Shi, A new simple third-order shear deformation theory of plates, International Journal of Solids and Structures, 44 (2007) 4399-4417. https://doi.org/10.1016/j.ijsolstr.2006.11.031 